\title{
Adolescent pregnancy and parenthood in South Africa
}

Carol E. Kaufman

Thea de Wet

Jonathan Stadler

Follow this and additional works at: https://knowledgecommons.popcouncil.org/departments_sbsr-pgy

Part of the Demography, Population, and Ecology Commons, Family, Life Course, and Society Commons, and the International Public Health Commons How does access to this work benefit you? Let us know!

\section{Recommended Citation}

Kaufman, Carol E., Thea de Wet, and Jonathan Stadler. 2000. "Adolescent pregnancy and parenthood in South Africa," Policy Research Division Working Paper no. 136. New York: Population Council. Version of record: https://doi.org/10.1111/j.1728-4465.2001.00147.x 


\section{Adolescent Pregnancy and Parenthood in South Africa}

Carol E. Kaufman

Thea de Wet

Jonathan Stadler

2000 No. 136 


\title{
Adolescent Pregnancy and Parenthood in South Africa
}

\author{
Carol E. Kaufman \\ Thea de Wet \\ Jonathan Stadler
}

Carol E. Kaufman is Healthy Ways Project Director, University of ColoradoHealth Sciences Center, and consultant, Population Council. Thea de Wet is Associate Professor, Rand Afrikaans University, and consultant, South African Medical Research Council. Jonathan Stadler is Project Coordinator, National Adolescent Sexual Health Initiative, Reproductive Health Research Unit, Baragwanath Hospital, and was Research Coordinator, Adolescent Health Program, Health Systems Development Unit during this project.

The authors are thankful for the comments of Cynthia B. Lloyd and Lutske Newton. They also gratefully acknowledge the generous support of USAID Cooperative Agreement No. CCP-A-00-94-00013-04 with the Policy Research Division at the Population Council entitled "Program for Understanding and Meeting the Needs of Adolescents." 


\section{Abstract}

South Africa's total fertility rate is estimated to be one of the lowest in subSaharan Africa, less than 3.0 births per woman nationally and declining. At the same time, adolescent childbearing levels remain high; more than 30 percent of 19 -yearold girls are reported to have given birth at least once. Using evidence from focus groups conducted in urban and rural areas in South Africa with young black women and men, and with the parents of teenage mothers, we consider the experience of early parenthood. Specifically, the analysis explores four aspects of teenage childbearing as it relates to key transitions into adulthood: the advent of a pregnancy and the decision to terminate or carry the pregnancy to term; the conditions under which "damages" (a fine for the boy's behavior that also effectively assigns paternity even if no marriage follows) are denied, paid, or refused; the impact of early childbearing on school, work, and marriage; and consequences of premarital childbearing on future relationships, including subsequent fertility. We find that in South Africa, in contrast to many other settings, teenage mothers may return to school once they have given birth and that this opportunity is strongly related to a long delay before the birth of a second child. Education is also strongly associated with the valuation of brideprice: girls who are better educated bring a higher price, which may encourage parents to support their daughters' schooling, and perhaps also their return to school following early pregnancy and childbirth. Babies born to teenage parents are extremely vulnerable. Because the baby is usually born premaritally and subsequent marriage between mother and father is uncommon, the support and maintenance of the child are subject to paternal recognition and commitment. The presence of a baby also generally means a lower brideprice for a future marriage; first-born children are sometimes kept secret from prospective grooms to maintain higher brideprice.

This material may not be reproduced without written permission from the authors. 
South Africa's total fertility rate is estimated to be one of the lowest in subSaharan Africa, less than 3.0 births per woman nationally and declining (South African DHS 1999). At the same time, adolescent childbearing levels do not appear to be changing. In 1998, over 30 percent of 19-year-old girls had given birth at least once (South African DHS 1999), a level approximating that experienced by their mothers and grandmothers before them (Preston-Whyte 1990). The persistent high fertility at young ages cannot be divorced from the broader trend in declining fertility. Many women who started childbearing as adolescents have few additional children in later life.

Increasingly, adolescents have opportunities that do not lock them into prescribed roles. Even if a girl has a child, she is not necessarily destined for marriage and subsequent childbearing. In contrast to circumstances in many other developing settings, schoolgirls in South Africa who become pregnant are not expelled and are allowed to return to school once they have borne the child. Indeed, across sub-Saharan Africa, increased education has profoundly changed the opportunities available to youth and altered the valuation of the timing of marriage and childbirth, particularly in urban settings (Bledsoe and Cohen 1993). Yet, most research has focused on the event of early pregnancy or first birth and their correlates, such as knowledge of reproductive physiology or contraceptive use, and has ignored the divergent pathways that lead from adolescence into early adulthood. Are girls under pressure to prove their fertility or does having a child before marriage decrease girls' prospects for a formal union? How do opportunities for education or work for teen mothers and fathers affect the timing of marriage or a second pregnancy? How does the presence of a child shape future sexual relationships and subsequent fertility? In the case of South Africa, these questions are closely tied to declining fertility: How does the separation of marriage and childbearing relate to small completed family size in later life?

To explore these issues, we use evidence from focus group discussions held in May 1998 in urban and rural settings in South Africa and described in detail below. The analysis will explore four aspects of teenage childbearing as it relates to key transitions into adulthood: (1) the advent of a pregnancy and the decisions to terminate or carry the pregnancy to term; (2) the conditions under which lobola, or "damages" (a fine for the boy's behavior that also effectively assigns paternity even if no marriage follows), are denied, paid, or refused; (3) the impact of early childbearing on school, work, and marriage; and (4) consequences of premarital childbearing for future relationships, includ- 
ing subsequent fertility. For each of these aspects, we compare discussions from each age, gender, and geographical subset of the focus groups.

The paper consists of four parts. First, we outline the theoretical developments and empirical record on teenage childbearing and on marriage and union formation for the region. We pay particular attention to Caldwell, Orubuloye, and Caldwell's (1992) thesis positing a "new" type of fertility transition for the region, a recent analysis of DHS trends by Kirk and Pillet (1998) and Cohen (1998), and the arguments put forth by Bledsoe and Cohen (1993). After describing our methodology and data, we describe the way in which each aspect of early childbearing and marriage unfolds for young people as they take on adult responsibilities. Finally, we briefly mention the theoretical and policy implications of our findings.

\section{BACKGROUND AND CONTEXT}

As a recent world population report on adolescent fertility points out, the number of births to adolescents in sub-Saharan Africa is projected to increase over the next few decades, exceeding a total of 4.8 million births to girls aged 15-19 over the period 1995 to 2020. The increase, some 400,000 more than 1996 levels, reflects both a growth in the size of the cohort of teens and the higher levels of fertility to teens in this region relative to levels in other parts of the developing world (McDevitt 1996). Evidence from the Demographic and Health Surveys indicates that while in some sub-Saharan countries the proportion of teens having births has declined slightly, the level of early births remains high: 68 percent of women 20-24 had given birth before age 20 in Uganda, 58 percent in Kenya, and 49 percent in Zimbabwe. Moreover, as age at marriage is rising, the number of premarital pregnancies is increasing, a phenomenon particularly apparent in urban settings (Bledsoe and Cohen 1993). These statistics are broad markers of reproductive behaviors that point to the pervasiveness of early births. The efforts of planners and workers in reproductive health have been driven by a concern to delay the first birth, but few have recognized that efforts directed at delaying the second birth may be equally important; the separation of childbirth and marriage in these populations and changing social and economic opportunities mean that delaying a second birth may significantly improve the life chances of the mother, father, and child. 


\section{Theoretical Developments: Fertility Decline and Adolescent Childbearing}

An impressive body of earlier research documenting persistently high fertility levels in sub-Saharan Africa had pointed to unique cultural practices and beliefs (Caldwell and Caldwell 1987), harsh socioeconomic conditions (World Bank 1986, 1993; Ainsworth, Beegle, and Nyamete 1994), and particular institutional structures or policies (Frank and McNicoll 1987) as seemingly insurmountable barriers to lowering fertility. Recent evidence of fertility decline in Botswana, Kenya, and Zimbabwe has provoked a reconsideration of fertility dynamics in the region. Debate now has shifted from whether fertility declines might occur in sub-Saharan Africa to which conditions precipitate and sustain them. Caldwell, Orubuloye, and Caldwell (1992) hypothesize that fertility declines in the region will assume a unique form, rather than follow an Asian model characterized by fertility limitation at older ages and later ages at marriage and childbearing. Instead, Caldwell and his colleagues suggest that the African fertility decline will occur across all age groups, driven by three forces affecting demand for contraceptive use. One is from older women who remain sexually active but do not wish to become pregnant because of proscriptions against childbearing for grandmothers, their economic or family-size concerns, or because they do not want to bear a child for a man involved with a younger woman. Another is for birth spacing purposes among married women; as postpartum abstinence practices erode, and women face increased pressure to resume sexual relations earlier, they will increasingly turn to contraceptives to ensure proper spacing between children. Finally, young unmarried women will exert considerable demand for contraceptives because most are sexually active, yet a birth would result in an abrupt end to education and to the promise of modern-sector employment. Caldwell and colleagues further argue that fertility declines at young ages will be greatest where there is little restriction on access to contraceptives for youth and unmarried women-a sharp contrast to the Asian experience in which little decline in fertility occurred below the age of 25 .

Caldwell et al. support their arguments using data primarily from Ado-Ekiti, a northern district of Ondo State, Nigeria. Although based on the experience of just one district in one country, their assertions are largely supported by recent empirical evidence from a survey of DHS studies throughout sub-Saharan Africa (Kirk and Pillet 
1998). The empirical findings of the Caldwell, Orubuloye, and Caldwell study suggest that their thesis might be especially appropriate for South Africa, since fertility there has fallen substantially. Furthermore, their explanation merits consideration for two reasons. First, it recognizes reproductive differences at various stages of a woman's life and thus provides a basis for thinking about differential fertility over the lifecourse. Second, they emphasize the role of youth in fertility change. Their description of the engines driving that change, however, are in reference to fertility across all age groups, and not specifically about those under the age of 20 (indeed, the survey from Nigeria does not include women below age 18). Conceptually, then, women of reproductive ages are treated as discrete groups, and not as girls and women who may experience several transitions throughout their lives. How is it that black women in South Africa who begin bearing children at young ages end up with small completed family sizes?

Caldwell et al.'s thesis prompts four lines of theoretical inquiry. First, the authors state that contraceptive demand by youth is in part to delay marriage. However, while some premarital births result in marriage, increasingly this appears not to be the case, especially in southern Africa (Singh and Samara 1996). Moreover, we know very little about the demand for contraceptives or about childbearing intentions for young single mothers or adolescent newlyweds, or their subsequent fertility experiences. Second, as the authors point out, adolescent childbearing often is associated with an end to schooling, especially for girls. Sometimes this is dictated by policy, sometimes by social norms or material conditions. Untangling the reasons why girls do not return to school is critical to appropriate policy development, which in turn could enhance postpartum social and economic opportunities (see McNeil et al. 1980). Are girls not returning to school because law prohibits them, because they have no resources for childcare while they attend, or because as mothers they are expected to stay home with their children? A third issue rests uneasily at the juncture of these two: brideprice. Far from disappearing in the face of modernizing changes, the system of brideprice has continued to operate, increasingly taking the form of monetary exchange valued according to a woman's economic potential, as indicated by her level of education and by her ability to bear children, potential or proven (Bozzoli and Nkotsoe 1991; Stadler 1994). Finally, the role of men and boys in adolescent reproductive dynamics is likely to be critical to lifetime fertility experiences. Boys and men have their own reproductive goals, particular concerns or prefer- 
ences about timing, and hold various notions of their paternal roles and responsibilities. These four domains provide a starting point for a reconsideration of reproduction, sexual unions and marriage, and adolescent progression to adulthood in sub-Saharan Africa.

\section{Adolescent Childbearing in South Africa}

High levels of early childbearing have been sustained over several decades, with 30 to 40 percent of women in each five-year age cohort having been teen mothers for around the last 40 years (Central Statistical Service 1997). Earlier reviews of the South African literature (see Caldwell and Caldwell 1993) suggest that while adolescent childbearing is not embraced, it is accepted. Preston-Whyte and her colleagues (1991) offer a succinct account that emphasizes the value both of children and of the demonstrated fertility of girls within families. According to this view, although unmarried daughters may be severely reprimanded for becoming pregnant, the baby once it is born is generally welcomed into the household, the girl usually returns to school, and the fact that she has proven her fertility may actually increase her chances for marriage in the future and improve her status in the short term. A recent study of black teens in three metropolitan areas of South Africa, however, presents a slightly different story (Richter 1996). Only 12 percent of the 16-19-year-old girls sampled indicated they wished to have a child within the next year or two; but of those, the majority stated that they wanted to do so to prove their fertility. Notably, most teens in this study indicated that they did not want to have a child until they had finished school and had a means to provide for the child.

Recently, researchers have paid more attention to the events leading to a pregnancy, including negotiation, sexual networking, and coerced or forced sex (Varga and Makubalo 1996; Wood and Jewkes 1997). These researchers find that girls rarely wish to get pregnant at an early age and often endure traumatizing situations both before the pregnancy (forced sex or rape) and upon the event of the pregnancy, when they often feel confused about their condition and the options open to them, betrayed by their partners, and unsupported by family members.

While interpersonal relationships are an important part of the story, so too is service delivery. Black youth in South Africa have been particularly affected by politics surrounding family planning services. In an effort to decentralize family planning services in the late 1980s, special clinics and programs for adolescents were discontinued 
(Kaufman 1996). While a large number of service delivery points exist in the country, adolescents often are not welcome. Providers of contraceptives in the national nursebased program have been notoriously unsupportive of teens, scolding them for sexual activity and refusing to provide them with contraceptives (Klugman 1988; Mfono 1998). In short, although the country has had an extensive family planning service, and some efforts are now being made to re-establish youth clinics or drop-in centers, services for adolescents have long been associated with judgment and hostility.

Quantitative data with which to assess trends in adolescent fertility, marital patterns, and contraceptive use are all but nonexistent in South Africa. ${ }^{1}$ The lack of demographic data has resulted in a thin base of systematic investigation on demographic trends over time, especially for adolescents. However, two recent studies have noted unique patterns of childbearing at young ages. Garenne, Tollman, and Kahn (1999) use demographic surveillance data from Agincourt, the rural area in which the participants in our discussions reside. The researchers document a double-spiked fertility pattern, one that peaks during teenage years, and another in the late 20 s and early 30 s. While the authors have little explanatory data available to them, they posit that many women who have births at a young age wait several years before having another child. In another analysis using demographic data from the late 1980s, Kaufman (1998) finds in her life table estimates of women's retrospective fertility reports that increasing proportions of women who began their childbearing as teenagers delay a second birth by at least four years. Extant demographic evidence suggests that in South Africa, early childbearing does not mean rapid or continuous subsequent fertility. While existing data do not readily allow exploration of why these patterns are emerging, educational opportunity is likely to be a contributing factor. While clearly the system as implemented under the apartheid regime was disadvantageous to nonwhites, in 1993 virtually all South Africans aged 1519 had completed primary schooling (Lloyd et al. 1999). Moreover, about 35 percent of black girls aged 19 and younger who had given birth at least once were currently attending school (Kaufman, Maharaj, and Richter 1998). The estimate can only suggest a causal link between education and delayed second births, but the low rates are a testament to the value placed on education even for those who have begun their reproductive careers.

As the dates of the studies reviewed here suggest, the changes discussed in this paper span apartheid and post-apartheid years. Transformations brought about by the 
end of apartheid are likely to have had an impact on adolescent reproductive patterns, but the extent of the impact may be impossible to determine. Appropriate "before" and "after" data are not available; social and political transformations began to occur in the mid-1980s and continued thereafter, making discrete changes difficult to track; and many changes, for example increased urbanization and expanding educational opportunities, would probably have occurred in the absence of political change, though perhaps at a slower pace.

\section{DATA AND METHODS}

As mentioned at the outset, we use evidence from focus group discussion in urban and rural settings to explore teenage parenthood in South Africa. The focus group discussions were held in May 1998 with teenage mothers, mothers in their 20s who had their first child before age 20, parents of adolescent mothers, and young men in their 20 s, some of whom were fathers. ${ }^{2}$ For each category, two discussion groups were conducted, each with different respondents to incorporate a comparative check on discussion content. Participants were chosen in a nonprobabilistic random fashion from various neighborhoods or settlements to ensure a broad range of experiences within each group. The vast majority of the young people with whom we talked were unmarried. Young men participating in the discussions were not required to be fathers because of the bias this might introduce to views on paternity, marriage, and future relationships. Table 1 provides a description of group characteristics. While no inference can be made from the distributions shown here, it is noteworthy that in urban areas, parents' age at first birth is below 20 years, while it is just above 20 in rural areas. Educational achievement of older teenage mothers is roughly equivalent to that of the young men's groups. These young women managed to attain about as much education as their male counterparts, who for the most part were not burdened with the care of a child.

The urban discussions were held in Soweto, a collection of townships southwest of Johannesburg. Under apartheid, blacks—who were considered guest workers in white areas-could live in Soweto while they commuted to the "white" city of Johannesburg to work for white-owned businesses or in white homes as domestic servants. Soweto is often the center of political challenge and protest currently, as it has been in the past. Economically, the area is diverse including shack settlements, modest middle-income 
Table 1 Characteristics of focus group participants

\begin{tabular}{lcccc}
\hline Participants & $\begin{array}{c}\text { Number of } \\
\text { participants }\end{array}$ & $\begin{array}{c}\text { Average } \\
\text { age }\end{array}$ & $\begin{array}{c}\text { Average } \\
\text { education }\end{array}$ & $\begin{array}{c}\text { Average age } \\
\text { at birth of } \\
\text { first child }\end{array}$ \\
\hline Teen mothers & & & & \\
Urban 1 & 8 & 17.4 & 9.5 & 16.4 \\
Urban 2 & 9 & 17.3 & 9.9 & 15.4 \\
Rural 1 & 6 & 17.0 & 9.0 & 15.3 \\
Rural 2 & 5 & 17.0 & 10.4 & 15.0 \\
Older teen mothers & & & & \\
Urban 1 & 5 & 26.0 & 11.2 & 18.2 \\
Urban 2 & 5 & 24.0 & 11.4 & 17.0 \\
Rural 1 & 8 & 24.8 & 11.4 & 18.0 \\
Rural 2 & 6 & 21.0 & 10.2 & 16.6 \\
Parents & & & & 18.9 \\
Urban 1 & 11 & 47.8 & 7.5 & 19.2 \\
Urban 2 & 7 & 44.1 & 7.6 & 22.7 \\
Rural 1 & 8 & 51.6 & 4.9 & 22.9 \\
Rural 2 & 9 & 55.1 & 5.3 & Number who \\
are fathers \\
Urban 1 & & & & 2 \\
Urban 2 & & 22.4 & 11.4 & 5 \\
Rural 1 & 8 & 26.8 & 10.6 & 2 \\
Rural 2 & 8 & 21.3 & 10.8 & 0 \\
\hline The Son & 8 & 23.0 & 11.9 & \\
\hline
\end{tabular}

aThe South African education system has changed a number of times over the past several decades. The numbers here are measured in "grades," the current system. Grade 12 is the final year of secondary schooling.

housing, and sprawling mansions. The area draws migrants from all linguistic groups of the country, and while blacks living in the area are almost all highly conversant in English, the vernacular is a combination of languages, predominated by Zulu and Sotho.

Another set of focus groups, again, two of each category, were held in the rural area of Agincourt, in Northern Province in the eastern side of the country. As in the case of Soweto, the geography and character of Agincourt were molded through apartheid 
policies. It was a part of the former homeland area of Gazankulu, and through the relocation and development policies of the 1960s and 1970s the residents were forced from scattered settlements into planned villages. Thus, while officially defined as a rural area, villages in Agincourt are characterized by surprisingly high densities, with many infrastructural problems common to urban areas. Most people living in the area are Tsonga- or Shangaan-speakers, and they participated heavily in the migrant labor practices of the apartheid era whereby men from homeland areas would contract themselves for up to three years to work in white-owned industries and on white-owned farms. While official migrant labor policies are no longer in place, many men (and increasingly women) migrate out of the area for substantial periods of time in search of employment.

The discussions were conducted in the local language and were recorded, transcribed, and translated; in both urban and rural settings the translations were checked by a second person. The analysis consisted of independently coding discussions by topic. The coding and interpretation of discussions were then cross-checked by at least one other person.

In the following sections, we present data from group discussions to illustrate the transition of adolescent parents into young adulthood. While we give ample space to the words of girls, boys, and parents who participated in our discussions, we also issue an important caveat. Discussions in Soweto invariably took on a lively and engaged character, and participants of all ages appeared to be quite frank about even very personal aspects of their lives. In Agincourt, the level of engagement varied, but the younger girls especially were shier and tended to offer less about their experiences.

The accounts given by young fathers and mothers in Agincourt and Soweto share much in common. Our analytic approach is to emphasize those experiences as expressed by participants in the discussions, using their own words to highlight contrasts and similarities. In the following analysis, each quotation is followed by notation indicating group and location. The designation "older mother" refers to young women in their 20 s who had their first child before age 20; "teen mother" refers to the group who were currently teenagers and mothers; "young man" refers to men aged between 20 and 30 (not necessarily fathers); and "parents" refers to the group of adults with sons or daughters who themselves became parents at an early age. 


\section{PREgnanCY}

\section{Why a Girl Becomes Pregnant}

We began discussions about the consequences of an early first birth by asking about the reasons girls become, or "fall," pregnant so young. The conversations largely supported the reasons adduced by other research on this topic: ignorance, curiosity, peer pressure or feelings of competition, fear of attending clinics unwelcoming to young contraceptive users, and occasionally forced sex or rape. In the following discussion, we do not cover all these topics as many are covered in prior studies. Instead, we focus on those topics where our discussions provided new insights, namely the role of education, parental or familial communication, and forced sex or rape.

Interestingly, in urban areas ignorance of the physiology of sex was not recognized as a legitimate excuse. Both girls and boys stated that sex education and information about sexuality and contraception are widespread; youth in this setting are thought to have sufficient factual knowledge about reproduction:

And also there is no child who does not know what is happening, sex education is a thing that is taught each and every day.

\section{Who teaches them?}

TV, radio, pamphlets, at school, books.... There is no child who can say they don't know. That is a lousy excuse. It is out [as an excuse]. I mean at school they are taught about it. (Older mother, Soweto)

The comments from these young people imply that other factors play a greater role than knowledge itself. Parents in our discussions did not always understand why adolescents have information but still make poor decisions:

Today's boys cause it [pregnancy] purposefully.... When I took my girl to report the pregnancy [to the father's family], his mother called me afterwards and told me how she told those boys to use condoms every time they sleep with girls, if they have to, but since they do, they must use 
condoms to prevent such things. So that is why I say today's kids are well informed. (Parent from Soweto)

However, many young women and men felt let down by their parents for not personalizing the risks sufficiently to make the message effective:

Does it happen that you blame your parents when you fell pregnant?

Yes I do, 'cause they don't talk to us, they are scared. Our parents thought that by telling us to go to the family planning clinic, they will be teaching us to have sex with boys. They don't talk to us. They are the cause of teenage pregnancy.

What must she [your mother] say?

Like now you are growing up and such and such could happen, she should be open. She'll sit down with you and say now you are a grown-up girl, as you are aware that you are now having your periods you can go to family planning for contraceptives. If you are having good communication with your mom you will ask her why am I supposed to go to the clinic. (Teen mother, Soweto)

While some girls mentioned sexual abuse or forced sex, these reasons were not mentioned in discussions about why girls fall pregnant. The topic of rape or forced sex was explicitly probed in urban discussions. The participants indicated that while occasionally it did happen, it was not common. Given the level of rape and sexual violence in South Africa (Wood and Jewkes 1997; Mail and Guardian, 9 April 1999), this response was somewhat surprising. Three explanations are possible. First, forced sex truly is not common or at least not in the lives of our participants; second, participants did not want to discuss it publicly; or third, coercion is such a common feature of sexual relationships that it is not recognized as violence, or girls and boys accept some level of violence within the relationship (for differing perspectives on the nature of violence in sexual relationships see Varga 1997; Wood and Jewkes 1997; Schalekamp 1998). In Agincourt, participants did not speak of violence or coercion directly, though these groups were not 
asked explicitly about their perceptions. However, girls do speak of boys "stalking" them and then "convincing" them to have sex. In both Agincourt and Soweto, adolescents rarely brought up the topic in connection with a cause of teenage pregnancy; however, they did mention violence in other contexts, for example domestic violence, killings in the community, and incest among friends or neighbors. Clearly violence is a part of life for many blacks, in both urban and rural settings. Nevertheless, to the extent that forced sex does occur, youth in our focus groups may understand coercion in relationships differently than researchers or the media do.

\section{Accepting a Pregnancy or Choosing Abortion}

Young people in our discussions struggled with feelings of betrayal regarding their condition, whether by parents, partners, or friends, but the event of a pregnancy forces both girls and boys to address difficult and immediate social and economic decisions. A pregnant adolescent must decide whether or not to continue the pregnancy, whom to tell about the pregnancy and when, and whether or not to leave school. For most girls, the decision to end a pregnancy is weighed against admitting to the pregnancy, the consequences a pregnancy would bring to her relationships with others, and the likely course of her own future should she carry the baby to term:

I told her [my mother] that the reason why I opted for an abortion is because I saw how she struggled, she was not employed, and it was grandmother's pension that we were living on. (Teen mother, Soweto)

I just wanted to have an abortion because of my parents. I knew they would be angry with me. Also my boyfriend-he refused to accept the pregnancy... I tried to have an abortion but it did not work out. I took the pill and I thought maybe it will work. When I told my sister about wanting to have an abortion, she said that I must not do it. (Teen mother, Agincourt)

Abortion, recently legalized in South Africa, is a highly contentious issue in this very conservative society, regardless of race. Nonetheless, both boys and girls in our discussions talked about their own experiences with openness and detail. The discus- 
sions on abortion in our study are select ones, however; these young women are mothers. Although one or two women admitted to a successful abortion in the past, most who contemplated termination in these groups either elected not to do so or were unsuccessful in their attempt. While opinions offered in the discussion were still imbued with conservative views, for some, difficulties surrounding the birth and care of a child softened those views. In other words, even though our groups probably over-represented conservative views, there was a striking lack of condemnation among the participants:

You get that [thought about an abortion]...first thing you come from a poor family, secondly you realize you are pregnant, thirdly you are still at school.... You look at your options and realize you cannot support this child and when it comes to a boyfriend you have no guarantee he will support you. You say: "Maybe if I get an abortion at an early stage, I might have the opportunity of going back to school." (Older mother, Soweto)

In both urban and rural settings most girls in our discussions had considered abortion and many of them had sought one. Commonly, abortion attempts were selfadministered, usually with a local recipe provided by friends or an older sister or aunt. Occasionally, a girl might approach a traditional healer or seek the services of a health professional known to provide abortions outside of formal health care institutions. Formal services were secured only if the arrangements were made by the mother, or occasionally a boyfriend, likely to be a "sugar daddy" who is eager to hide an extramarital pregnancy. Sugar daddies, usually older married men who provide girlfriends with gifts or money, are the "boyfriends" who have the social motivation and the economic means to encourage an abortion. (While legal abortion is free now in the country, not everyone knows this, and for the many who seek alternative sources to terminate a pregnancy, non-formal services are not free.) If sugar daddies are more likely to arrange for an abortion for their girlfriends, the young men in our discussions generally expressed negative views of abortion:

I won't allow it, I will make her life horrible to a point that she would not believe it's hers. (Young man, Soweto) 
I won't allow her, destroying my child in the toilet. (Young man, Soweto)

While the statements are often strongly worded, boys who take the moral high ground may do so because they have not actually been confronted with this situation, or because they felt unable to express their true views in the discussion. According to young mothers, however, taking responsibility for the pregnancy and making a commitment is unusual for fathers. Abortion seems to be an easy solution:

What happened to me when I was pregnant [was that] when I told my boyfriend, he told me to have an abortion. He won't manage to have a child. [He said]: "You are not working and at my place they don't like children and I am still young." (Older mother, Soweto)

My boyfriend was not happy about my pregnancy because he said to me that I must go and have an abortion. (Older mother, Agincourt)

In the rural community, abortion is further stigmatized by a belief that sleeping with a girl who had an abortion or miscarriage and had not been ritually cleansed would lead to death:

Other girls have an abortion before you know her, and at that time that I sleep with her I will die. Because it is dangerous to sleep with someone who has had an abortion-her blood will be hot. ${ }^{3}$ (Young man, Agincourt)

Even in a setting where abortion taboos are strong, however, some boys accept that it may be the most appropriate choice:

The girls are right when they abort if boys refuse the pregnancy. How can they manage to support their children without their fathers? (Young man, Agincourt)

\section{Response of the Family}

Once a decision has been taken not to terminate a pregnancy - a resolution that in some cases occurs quite late in the pregnancy_-girls and boys encounter various re- 
sponses as they admit their impending parenthood to friends, families, and parents. Generally in both urban and rural settings, parents are upset and angry, and participants frequently mentioned that girls would be thrown out of the house, at least for some days, or family members might not speak to them for months. Many of the stories told in the focus groups support the thesis that babies born to adolescent girls are eventually accepted into the family (Preston-Whyte et al. 1991).

They [my parents] chucked me out of the house. I went staying with my aunt and she asked me when last did you have your periods and I said last month [lying]. They found out and my father chased me out of his house and out of my aunt's house. I went to stay with my maternal grandma. After four days he [my father] came and took me home. (Teen mother, Soweto)

However, the discussions indicated that few girls saw early motherhood as a way to prove their fertility or improve their marriage prospects. Instead, young motherhood often brought censure from parents and abandonment from partners:

My parents wanted me out of their house, saying that I must move and stay with my boyfriend and my boyfriend was negative, saying he wants an educated woman and I was still a high school student. (Teen mother, Agincourt)

Among most African groups in South Africa, girls and boys traditionally do not discuss sexual matters, including premarital births, with parents. Often, adolescents who find they will soon be parents elect to use a relative, often an aunt, uncle, or same-sex elder, to convey the news to their own parents and to intercede for them:

When I became pregnant, she [my mother] chased me away. She stayed a long time without talking to me. My grandmother sat down with my mom and talked to her that I am her child, and then my aunt and my grandmother took me home. (Older mother, Soweto) 
If it is hard to tell your parents, tell your aunt or your kokwana [elder]. (Young man, Agincourt)

While many parents do eventually accept the pregnancy and the social and economic consequences, some do not. Girls who are without the support of their partners or family members, especially mothers and grandmothers, are left to fend for themselves:

I never got any support from my parents, even a maternity dress or something to eat. (Teen mother, Agincourt)

My mother never bothered, I had to pull on my own, I went through hard times... With me I was lucky, I even got male admirers who gave me money and that is basically how I pulled through. (Teen mother, Soweto)

Teenage pregnancy is common in both urban and rural areas. Adolescent pregnancy is not easily accepted or readily accommodated by partners, families, or the pregnant girls themselves, however. Girls struggle with decisions about keeping the baby, but this decision is often influenced by partners or families. The newborn child is usually cared for by the parents of the young mother or father, and an additional child to feed and clothe is often a heavy economic burden. The familial ties that a child born outside of marriage carries, then, are particularly critical. Those ties are often defined by paternity, and subsequently by the nature of the paternal recognition of the child.

\section{PATERnity AND DAMAgeS}

Establishing paternity for the child is a critical moment determining many of the long-term social and economic consequences for the young parents and their child. Establishing paternity means that the girl's family has claim to economic resources from the father's family to support the child. It also means that the child has a cultural and social connection and recognized identity within the community, whether or not marriage ensues. Indeed, marriage often does not follow a premarital birth. We consider marriage and brideprice (lobola) practices in more detail below, but the often loose association between marriage and childbearing means that paternal identification as- 
sumes greater significance: lobola may or may not be paid, but paternal acknowledgment may result in economic compensation (“damages"). In this respect, acknowledging paternity varied considerably between urban and rural settings. In Agincourt, paternity is rarely questioned. In Soweto, while boys' acceptance of paternity does happen, it is increasingly an ideal. Girls and boys both assert that boyfriends do not want to assume the financial and social obligations of parenthood:

Most of us, when a girl says "I am pregnant," we normally deny it. We don't even support by buying her just one nappy [a diaper], you run away from that responsibility knowing fully well it is yours. (Young man, Soweto)

Accusations of promiscuity and multiple partners produce a reluctance among boys to admit fatherhood:

She used to go around with other boys and when they came to me [about the child] I denied it. (Young man, Soweto)

Sometimes, financial consequences of accepting one's responsibility act as a strong disincentive to admit paternity:

I won't agree to damage. I have to support that child and I am still at school. It is costly to attend school and getting a job as well. Pay damage on top of what I am going to pay for maintenance as well...no. (Young man, Soweto)

In Soweto, a boy or his family may provide a "conditional" acceptance of paternity. A boy agrees to acknowledge that he is the father if the child is born with physical features characterizing his family, for example shape of head, ears, special marks, or color. Boys and their families feel this is a safeguard against supporting children who do not belong to them, whereas many girls find this practice carried to absurd lengths:

[Damages] are paid after the birth of the child and after the child has been identified. The boy's family will come to identify the child. They will even check the baby's ankles to see if they are matching one of their family 
members even if it is the great-grandfather or mother who passed away many years ago. (Teen mother, Soweto)

I won't support before I can see what kind of a child comes out. If I can tell this is my blood, then I can support her. I can tell myself that this is my girlfriend. I won't just go around buying things not even having sight of the child. I want to see it first and then I can start doing things for her and that his colour matches mine but if not, I will tell her there is something wrong here. (Young man, Soweto)

Once paternity is established, the boy and his family are expected to pay a fine, commonly referred to as damages, and contribute to the support of the child. Payment of damages symbolically states that the newborn is a child of the boy in question. The actual meaning and significance of "damages," along with its value, are, however, a subject of much debate. In general, damages were meant to provide compensation to the girl's family for the decreased value they would receive for her brideprice (lobola) since she had had a child with another man:

If you are young, the damage will be more so that if you happen to marry somebody other than the father of your child that money will cover for the shame. (Teen mother, Soweto)

Many respondents stated that the fine indicates the boy would be responsible for future maintenance of the child even though he will not marry the mother:

You know in Tswana [culture] it is like this, if you had a child at a young age, this does not necessarily mean that these people are getting married. There is this thing called damage. They take out a certain amount of money. This means that a boy can have access to his child. (Young man, Soweto)

Damages are also sometimes considered a "downpayment" on brideprice. Marriage in South Africa, as in many other settings in sub-Saharan Africa, is often processual, with brideprice obligations met over a series of payments. Considering damages as a 
part of brideprice payments is not inconsistent with the way in which marriage arrangements are brokered:

Like in my case, for Celiwe [her daughter] they [the man's family] paid damages and 1 percent of it is for lobola. When the guy comes back to pay lobola we are going to subtract that 1 percent, i.e., if we want R10,000 we will subtract R1000 [sic]. Even if the other boy, not the father of Celiwe's child, wants to marry her he'll pay the same thing. (Parent, Soweto)

Commonly, however, damages are considered to be a one-time payment, an admission of guilt and fatherhood. The payment of the fine in practice leaves open the possibility of future support from the boy and his family, or, conversely, allows the boy to return to claim the child at a later date. Still others acknowledge that accepting paternity does not necessarily require any obligation:

Some say OK we acknowledge the baby but they won't do a thing for the baby. (Teen mother, Soweto)

In Agincourt, the tone of discussions about paternity and damages was qualitatively different. While rites of damages were immediately acknowledged and their role affirmed, no one offered details about personal experiences of paternity or damages. Questions of paternity or of verifying paternity through physical features of the newborn were not salient in this community. Paternity would either be flatly denied or readily accepted, and discussion about the consequences of a pregnancy focused on the obligations of the boy and his family. The course of action may be influenced by the constraints facing the boy, the resources available to the boy's household, and sometimes educational aspirations. Tsonga society is virilocal, and girls traditionally move to their partner's house upon marriage (or settlement of lobola arrangements). In the case of a premarital pregnancy, the expectation is that the girl will move to the boyfriend's house:

My parents never had any debate with me. They just dump me to the boy's family. Even today I'm staying with my boyfriend. And my boyfriend is not working. We are suffering. (Teen mother, Agincourt) 
If this is the course of action taken, the girl's education will likely end, and the resources that might have gone to the boy may now be allocated to support his girlfriend and the new child:

If you are at home suffering they will want you to stay with your wife, so the money they [parents] used to give to you for school they won't give it to you again, it supports the girl. (Young man, Agincourt)

In practice, a premarital pregnancy in Agincourt no longer means the girl automatically joins her boyfriend's household. Boys' discussions focused particularly on the financial and educational impact of bringing a girlfriend and baby into the home. Girls, perhaps already accepting a truncated educational future, most commonly expressed concern over financial support. Traditional avenues such as joining the father's household are no longer guaranteed, and quite often the girl's own household has few resources available for another child.

\section{lobola, Marriage, And Teenage Parenthood}

Pregnancy, marriage, and lobola were once tightly associated in South Africa. Lobola may be translated as bridewealth, an economic exchange joining two families, as well as the transfer of rights over the labor and potential childbearing capacity of the woman. In many settings, the economic exchange has shifted from a transfer of property to a transfer of cash, and many assert that the symbolism of joining families has been subject to exploitation:

When they say lobola ...it was there from way back an old custom. It is a way of showing your respect from the girl's family, long ago they used to pay with cows. Nowadays things have changed. Cows have turned into money. It is now to prove that you can manage. (Young man, Soweto)

Our parents should not ask mega bucks when asking for lobola, it's hard to live these days. It's like they are making business through lobola. (Young mother, Soweto)

The meaning of lobola has changed, as has the actual cost associated with its payment. Previously, the standard cost was approximately 12 cows. Currently, the cash equiv- 
alent is about R10,000 (or about US\$1600) but the actual figure is largely determined by the educational status of the bride and the number and paternity of her children.

The high levels of early childbearing in South Africa, mostly premarital births, have coincided with weakened links between reproduction and marriage. While the sequence of demographic events — marriage, followed by birth—was probably never as orderly as many would describe it, the varied paths to family building in South Africa have caused a reevaluation of traditional beliefs. Many boys and girls describe childbearing as a means to cement a relationship. The advent of a birth, however, usually brings about very little to fulfill those original expectations. Marriage may be especially unlikely if the boy has already fathered other children:

So they [young men] do not get married because they have many vegetables [babies] around the area. [This] term is used because they are all different with different mothers_-potato, onion, broccoli, and so on-all they share is the father's surname, a vegetable. (Teen mother, Soweto)

The parents of the boy in my case were not happy because I was not the first girl he had made pregnant. So they did not know what to do about me as well as the other girl. (Young mother, Agincourt)

In both urban and rural areas, marriage was considered to be a step that ideally should be taken later in life, after completing education and securing an income. The rationale for marriage, however, differed substantially between the two settings. For rural girls, marriage represented a potential economic safety net, especially for those lacking their own familial networks of support:

I am thinking of getting married because at home we are very poor. If I can get someone who wants me it may be better. (Older mother, Agincourt)

Few girls from the urban areas thought of marriage in economic terms. While most thought it would occur, and many were looking forward to a marriage later in life, some expressed strong negative opinions about marriage: 
I don't want to get married. There won't be a man in my house, he will come visit and afterwards take his jacket with and leave. I don't want to be bullied, I don't want to be abused. (Teen mother, Soweto)

I don't want to, but my mother wants me to get married, I will do it to please her. Some people would rather be a "return soldier," a divorcée, rather than not tasting marriage at all. (Young mother, Soweto)

Most young men viewed marriage positively and as something that should happen when they are older. ${ }^{4}$ However, the ambivalence boys express about marriage is tied to expenses related to lobola:

You see, lobola is one of the reasons why men do not want to marry. They [want to] vat and sit [live together without getting married]. I personally think I am going to do it. I don't want to get married. I think it must be like this: If I pop out R5000 [for lobola], the girl's family must also give R5000 and we will see what to do with it. (Young man, Soweto)

Boys don't want to get married, girls leave home and stay with boyfriends, have kids with them, she will cook, clean, he will say he has a wife so why should he pay lobola. (Parent, Soweto)

Paying a large sum of money for lobola is considered very risky by some young men: If the woman leaves, will the man get his money back?

Lobola is not a problem. It is easy to pop out money, the problem is that when a time comes that you no longer like her and then you think of the money that you have spent. Rather not get married at all. (Young man, Soweto)

And according to the girls, boys probably will not get their money back:

Money for lobola doesn't go back to the boy's family no matter what. (Teen mother, Soweto) 
They won't get it. What about your body, your hands, will he give that back also? (Teen mother, Soweto)

While boys and girls both have some objections to marriage and lobola, lobola is generally accepted as central to formalizing a union between two people and their families. Education and lobola are tightly linked, in terms of suitability of partner but especially in terms of price. Historically, productive and reproductive labor have been a part of lobola arrangements. The groom and his family provided cattle to the bride's family to join lineages symbolically, but also materially to make up for the loss of productive power in the bride's natal household. The education of women, and the cash economy in which most participate in South Africa, have blurred the obligations of lobola. Education is linked to access to employment. Educated women are more likely to find relatively well-paying jobs and thus are usually valued more at lobola negotiations, but the groom and his family are not always willing to accept higher costs associated with educated brides:

It's ridiculous to charge R10,000 if that person is not educated, she won't bring any money at home from work. (Parent, Soweto)

[The boy's family] will tell you that they don't want her education, only your daughter. You can take her education and keep it. Some say that.... Take your education and give us your daughter only. (Older mother, Soweto)

A premarital birth initiates a reconsideration of familial obligations for lobola. While commonly the existence of a child reduces the "price" of the bride, especially if the child is not the groom's, this is not always the case:

She must be expensive as the child she has will end up working for youif she is a girl you will be the one who can charge lobola. (Parent, Agincourt)

Tensions over the economics of marriage and lobola are complicated by the potential of education and what an educated partner might contribute to a marriage. In 
South Africa, where women on average achieve a higher level of education than men, the discussion about suitable partners and the financial expectations of partners is taking on increasing importance. Women have traditionally provided their labor, both reproductive and productive, to the man's household. Given the monetary valuation placed on higher education, women now have much greater earning potential than previously. The stereotype of the husband holding the economic power in the household is no longer true; a few participants noted these changes and the implications they may have for relationships:

If you find a boy who is not married he is not working so he will find himself a nurse at Bush hospital, at Matikwane and Acornhoek [three nearby hospitals] in order to get money from them, for money not love. (Young man, Agincourt)

What is more is that they [women] do not want to get married [to me] because of social worker and doctors...me I am nothing. Maybe I only have a matric [completed secondary school]. So if you want to marry her she will refuse. (Young man, Agincourt)

Most women nowadays are educated and are working so they tell themselves that it is better to stay on their own at their own place and not to be married because they have everything there, and there is no need to stay with a man. (Young man, Agincourt)

Some young men find that marriage may be a key to financial stability, while others find themselves economically unappealing to educated women. The last young man quoted above was referring to a relatively new but increasingly common practice in Agincourt: women are paying their own lobolas. Marriage is not a prerequisite for having children, and if a woman can provide for her own economic wellbeing and that of her children, she may see no need to formalize a relationship. Presenting her father with lobola that she herself has earned also formally releases her from economic obligations to marry.

Conflicting descriptions of lobola and how education or the presence of a child might affect marriage negotiations underscore the dynamic character of the institution. The practice of lobola has not subsided with the advance of Western influences; instead, 
it has taken different forms with different meanings. Indeed, lobola may be more accurately understood as a practice with variable parameters; marriage and lobola - and its commensurate obligations - are not taken for granted, nor is there a set price. In Agincourt, for example, lobola may be used as a strategy to delay marriage. There, once a girl is married, her parents no longer provide for her school fees. If lobola is expensive and payments are strung out over a long period of time, her chances of remaining "unmarried" and in school increase. Conversely, if lobola is less expensive, repayment upon the conclusion of a failed relationship is easier:

I want less money, because next time if I want to go back home it will be easy for me to return home. (Older mother, Agincourt)

\section{SCHOOL, WORK, AND CHILDCARE}

South Africa has one of the highest levels of educational attainment in sub-Saharan Africa. Education is highly valued in urban and most rural settings, and is understood to be the key to good jobs and financial security. In South Africa, where unemployment levels can be as high as 60 and 70 percent in some areas, competition for employment is high, and education is perceived to be a determining factor in gaining access to decent job opportunities. Even in rural areas, such as Agincourt, being well educated means having received some tertiary training at a university or technikon:

I want my wife to go to school and I also want to go until we have finished matric. Then I will try to find a job somewhere else so that I can take my wife to college. (Young man, Agincourt)

Under these circumstances, leaving school before completing secondary education is a sizable handicap:

I cannot drop my studies because of a child. I will have to go back to my school and try to finish. (Young man, Agincourt)

You can find other people advise the girl to go to school again otherwise she will start suffering later on in life. (Young man, Agincourt) 
In most developing-country settings, having a child marks the end of education for girls, sometimes also for boys. In South Africa, however, many young mothers return to school after the birth of the child, following a policy formalized in 1996 but informally upheld by many school principals prior to that. Indeed, in 1993 approximately 34 percent of all girls under the age of 24 who had had a child as a teenager were currently attending secondary school ${ }^{5}$ (Kaufman, Maharaj, and Richter 1998):

When you go back to school, you find that there are a lot of girls who have children, they are many and they do go back. (Older mother, Soweto)

Returning to school, however, is not a given. For girls in Agincourt, and sometimes in Soweto, pregnancy and birth often meant moving to the home of their boyfriends, where they are subject to the financial decisions of in-laws. In Agincourt, the additions to the family could mean an end to education for boys as well:

Do boys go back to school after they've had their child?

You can go back to school if your parents can afford to support you. If not you will remain at home and look for a job. (Young man, Agincourt)

In both urban and rural settings, girls were primarily responsible for seeing to childcare, and families were not always willing or able to accommodate the schedule of a young mother attending school:

Others are not able to return to school because their mother refuses to look after the child while they are still in the school. (Parent, Agincourt)

What makes other teen mothers not go back to school?

Problems. Some do not have a babysitter, and their parents tell you she is yours. I took care of you, and you should also take care of your own. (Teen mother, Soweto) 
Moreover, parents or others making educational decisions in the household may believe that having a child marks the beginning of adulthood and adult responsibilities:

Some tell you go look for a job, mothers do not attend school. (Teen mother, Soweto)

For boys, the need to make payments for damages, child maintenance, or lobola often implies leaving school to find work:

I can be happy if they [parents] wait for me to be finished with my matric first. Then I can go around and look for a job even in the mines or in the firms. (Young man, Agincourt)

Sometimes you have a child you see it as a problem. Both of your families are poor. In that case a girl should go back to school and I must go and look for a job. I mean I am a father now and I am no longer a boy. If my child cries I will end up also crying. I must go and look for a job. (Young man, Soweto)

Returning to school is a goal for most girls, and many return shortly after giving birth:

I gave birth to my child on the 18th of January and the school reopened on the 14th. The next month which is February I rejoined the students. (Teen mother, Soweto)

Other girls are not able to return so quickly and withdraw from school for a period of time after the baby is born:

If your parents are strict you stay at least a year raising your child. The following year, if you attend school near your home, you go home during lunch time to see the child. (Older mother, Soweto) 
Young mothers want to return to school quickly and in fact view staying out of school as a punishment:

I got a child in '93 and '94 I went away to finish school. They [the parents] initially refused to pay school fees but when they saw that I was progressing at school, they agreed to pay. When I passed my matric in '94, I thought that in ' 95 they would send me to tertiary school. But my mother reminded me about my responsibility toward the child. So in '95 and '96 I was at home. Three years full, that was the punishment I got.

Was it a punishment?

Yes, it is a punishment. My peers are succeeding, while I am sitting at home. A child prevents you from progressing. A child disturbs you. And there is nothing you can do but raise him. (Older mother, Soweto)

My grandmother told me to stay at home. She told me she was doing this so that I should not do it again. Till now I don't have another child and I don't think I want another child. (Older mother, Soweto)

The value placed on education in South Africa has meant that, while not all young parents are able to return to school, most wish to do so, and over a period of time many are able to complete secondary school. The possibility of returning to school and the hope of continuing on to some tertiary training prompt many women to wait some time before having another child.

\section{“A SECOND CHILd IS NOT A Mistake": RELATIONSHIPS AND SUBSEQUENT FERTILITY}

In many sub-Saharan African countries, childbearing begins at early ages and continues throughout the reproductive years, with several years between children owing to extended breastfeeding practices and postpartum sexual taboos. In South Africa, early childbearing remains common. On the other hand, the country has experienced significant declines in fertility levels. Early age at childbearing is associated with a small com- 
pleted family size, a new pattern of fertility in the region. In earlier sections, we discussed changing patterns of marriage and paternity, the importance of education, and the social and economic difficulties posed by a new baby to young mothers and fathers. In this section, we examine the way in which these factors interact to determine the timing of the next child for young mothers.

For the young mothers in our focus groups, a virtual consensus emerged on the desirability of delaying the next child for many years — even of ceasing future childbearing-as exemplified by these remarks:

If it was me-I don't need any child in my life! That one I have is okayno more.

I don't want any more children in my life. Because if I separate with the father during the time I am pregnant, I will suffer so much. I don't even care if I don't get married.

I would like to have another child if everything is settled—such as education money and marriage. (Teen mothers, Agincourt)

How long should we wait [to have another child]?

Fifteen years is also fine. I have had it! (Teen mother, Soweto)

The completion of studies, financial security, and a stable relationship were the most commonly mentioned requirements to be met before having a second child. Of these, securing a stable relationship was viewed as the most difficult for a single parent. The presence of a child poses several obstacles to sustaining future relationships. In both urban and rural areas, girls and boys expressed great reluctance to become involved with a partner who already had a child:

I want to go with my child where the guy is staying. I will tell him firstly that I have a child. So then he will still love me if it is like that. If he does not then I will not stay with him. (Older mother, Agincourt) 
It is wrong for the father to see the child because they [previous boyfriend and young mother] may become lovers again, and my wife may be using the child to control two men. (Young man, Agincourt)

For me to take the child with the mother it is confusing. Even if you leave the child at home you will still support that child, meanwhile it is not yours. (Parent, Agincourt)

Many respondents expressed concern over the future of the child:

Sometimes when you are now pregnant with his baby, they tend to take care of their own and forget about the other one. (Parent, Soweto)

And others pointed to the uncertainties associated with bringing a first child into a new relationship, hinting at the violent world in which many South Africans live:

It is not good to go with your child to your second marriage. Because if it is a girl the man will try to sleep with the daughter when I am not around. (Older mother, Agincourt)

I do not think it will be a good thing to go with your child to your new husband because the time that you are not at home he will kill your child because it does not belong there. (Teen mother, Agincourt)

The difficulties of having a child from a previous relationship accepted into a new one has caused some young mothers to send their first-born children elsewhere, usually to grandmothers in rural areas, and sometimes surreptitiously, as described in this discussion among parents from Soweto:

Some parents hide the child, when the girl gets married, and that kills that child's future and when the granny that stays with the child passes away, now the problem erupts and the husband did not know that you had a baby. 
What is the reason for parents to hide that child?

The reason is to pretend your child is childless when marrying.

They want high lobola, because the girl got married without having a child.

Others are scared that their boyfriends won't marry them if they tell the truth.

Others took lobola back because the girl did not tell the boyfriend that she has a child at home.

Sometimes you hide a child and after marriage don't have any. Your husband will take you everywhere from gynecologists to traditional healers. It won't be easy now to say I had a child before. (Parents, Soweto)

Boys also consider these circumstances in their discussions about relationships with girls who already have a child:

I will never marry a woman who has a child. If the child has done something, she will not tell me, she will tell her mother that I am mistreating her child, and when I have a child with her she will love her child more than the one I have with her. So she mistreats our child. It is better to marry a woman who has your child. You never know she may be a snake if she comes with her own child. (Young man, Soweto)

I can't understand what he is talking about...when you look at her she attracts you and you don't know if she has a child or not. And some take their children to the homelands and they won't tell you. Sometimes you are even married to that girl when you learn the truth and then your lives change. So if you find that out, what would you do? Divorce? (Young man, Soweto)

The presence of children is often an obstacle, whether actual or perceived, to future relationships. Some adolescents choose to send the child away, others choose not 
to engage in a new relationship because of the child. Many carry the hope that these extreme options will not be the only ones:

My new boyfriend...does everything for [my child]. He even buys him clothes and pays his school fees. And he has not as yet spoken about another child. He must talk about marriage first before anything else. (Older mother, Soweto)

All young mothers in our focus groups were adamant about delaying the next birth. Indeed, the circumstances of young motherhood may be such that a teenage pregnancy is accepted, especially if the young parents (usually the mother) set goals for their future, including education and employment:

I can say that it is better for her to plan first and take the first-born to school and after that carry on working and then she can have another child. (Young man, Agincourt)

I want to have my second child in six years. I will be able to finish my studies and have money to support them. (Older mother, Agincourt)

If the girl wants to be respected after she has had her pregnancy she must return to school in order to finish and study and then she will be respected. (Parent, Agincourt)

A second pregnancy, however, following closely upon the first, is considered irresponsible, short sighted, and limiting:

She knew already that if she does not protect herself she would have another child. I don't understand what made her have another child. It was her own carelessness, a second child is not a mistake. (Older mother, Soweto)

Some girls want to keep their boyfriends. Like there is a certain girl in my street, she has two children. Her first-born is two years old and the other 
one is still young. She did all this just because this guy has left her with the house. She stays there with him and she does not want to go back to school. She left school in Standard 5. So she has reached her destination. (Older mother, Soweto)

Finally, others believe some girls follow a calculated reproductive strategy:

What others do is, if the boyfriend's family is well off, they try and get pregnant again so that that boy will be sort of entitled to her and never leave her. (Teen mother, Soweto)

Rapid and continual childbearing for an adolescent mother is no longer a norm in South Africa. All participants in our discussions could relate stories of such young mothers, but their own stories were almost always about finishing school, providing for the child they had, and then maybe entering a new a relationship and having another child.

\section{CONCLUSIONS}

Caldwell and his colleagues argued that fertility levels among adolescents in subSaharan Africa would drop during the course of fertility decline. In South Africa, where fertility is the lowest in the region, the prevalence of teenage childbearing in fact changed very little over the second half of the twentieth century. However, shifting opportunities available to adolescents, especially girls, during this time have had a pronounced effect on fertility after the first birth. The foregoing discussion outlined some of the most important shifts through the experiences recounted by adolescents and adults in our focus groups. Of the many decisions young parents face, perhaps no factor held more influence than education. Opportunities for education, even beyond secondary school and especially for girls, provided a direct incentive to delay a second birth. Indirectly, more highly educated women tended to command a higher brideprice: parents thus have incentive to keep girls in school longer. Finally, education and the employment opportunities it offers also provide a means for girls to carve out their own futures. Women who are able to achieve financial independence may be better positioned to negotiate the 
terms of their relationships, for example through purchasing their own lobolas and thus releasing themselves from obligation to marry, or simply by providing for themselves and their children so as to reduce or eliminate the economic dependence on husbands or partners.

Contrasts exist between our urban and rural settings. In rural Agincourt, for example, participants tended to mention witchcraft or traditional remedies for induced abortion or contraception more often than in urban Soweto. The tightly knit community in Agincourt also meant that concealing pregnancies or denying paternity is much harder to do there than in Soweto. Educational and financial support was a regular source of tensions in both areas, as were changing expectations about the next life stage after a teenage birth. In both areas the support of families and, increasingly, of teachers was critical to continued schooling. Returning to school after giving birth, however, is not easy, because of the hardship in organizing time for both studying and parenthood. Many girls and some boys fall behind in school, they are teased by fellow students and teachers, and, worse, some have to confront teachers who had made sexual advances toward them previously, or indeed had fathered the babies born to girls.

Another theme arising from the discussions is the economic and social uncertainty facing teenage parents and their children. While most families try to provide for the newborn child, many are born into conditions of limited resources with uncertain ties to a larger kin network that might be expected to contribute toward health care, clothing, or education. Indeed, the child may be sent away as a strategy to improve the life chances of the mother. Grandmothers, often the ones to take in the child, have for generations raised grandchildren. While this strategy in itself may not be harmful, we know little about the fate of first-borns given the difficult conditions of their birth.

Finally, many of the discussions were about past and future relationships, including sexual ones. Yet, there was a noticeable lack of mention of AIDS or condom use. We did not investigate this issue explicitly, but, with only two exceptions, mention of AIDS and condom use was absent in our discussions with young men. The participants did not seem to link sexual activity with safe sex or condom use. The lack of discussion is discouraging in light of an HIV-positive rate, at the time of our focus groups, of 16 percent among South Africans aged 15-19.

For young parents, adolescent childbearing poses many challenges and requires many compromises. Past research has investigated the determinants of childbearing in 
an effort to understand why levels remain high, especially in sub-Saharan Africa. Our research indicates that while many young parents regret the events that led to the pregnancy, most have worked out a way to care for a child. That experience and the opportunities in education and in subsequent employment have compelled many to postpone having a second child. Whether the pattern that has emerged in South Africa will hold true for other countries in the region is still uncertain. Nevertheless, the case of South Africa provides a convincing argument for policies that allow young mothers to return to school.

\section{Notes}

1 Demographic inquiry was highly politicized under apartheid, and consequently few studies exist (Kaufman and Phillips 1995). Obstacles related to data access and availability continue to hamper demographic analyses. Data from the 1998 South African DHS are not yet available; published 1996 census data are not available in appropriate form; micro-data census samples are quite expensive; and census data contain only limited information on adolescent fertility and marital patterns in any case. As Mensch and her colleagues point out (Mensch, Bruce, and Greene 1998), most standard surveys and censuses do not adequately address the special needs, opportunities, and constraints of adolescents and their health needs.

2 Because teenagers are sometimes reticent to admit recent childbearing experiences, we included a group of "older" teenage mothers. These young women probably had experiences similar to teenage mothers since the age difference is not great, but it was thought that the older group would be more open and have more years of postpartum experience upon which to draw.

3 "Hot" blood is polluted and is a major cause of illness according to local belief. Blood is thought to be absorbed during sexual intercourse.

4 In Agincourt, boys commonly assume that the years before marriage should be dedicated to sexual practice and seeking "compatibility" by having sexual relationships with different women. Specifically, if a man and a woman have sex, 
and either partner does not enjoy this fully, then their blood is incompatible, which indicates few children, and unhealthy ones. According to a young man from Agincourt: "You can find that she does not go with or match with your blood. When that happens you will think to meet someone else."

5 Because of repeated grades, late age of entry into primary school, and periods of withdrawal from school for financial, health, or political reasons, the distribution of ages for any given grade is quite large, especially for blacks.

\section{References}

Ainsworth, Martha, Kathleen Beegle, and Andrew Nyamete. 1994. "The impact of women's human capital on fertility and contraceptive use in Sub-Saharan Africa: A study of fourteen African countries," paper presented at a workshop on "The Determinants of Fertility in Sub-Saharan Africa: The Policy Implications of Recent Research," 10 May. Washington, DC: The World Bank.

Bledsoe, Caroline H. and Barney Cohen (eds.). 1993. Social Dynamics of Adolescent Fertility in Sub-Saharan Africa. Washington, DC: National Academy Press.

Bozzoli, Belinda and Mmantho Nkotsoe. 1991. Women of Phokeng: Consciousness, Life Strategy, and Migrancy in South Africa, 1900-1983. Johannesburg: Ravan Press.

Caldwell, John C. and Pat Caldwell. 1987. "The cultural context of high fertility in subSaharan Africa," Population and Development Review 13(3): 409-437.

- 1993. "The South African fertility decline," Population and Development Review 19(2): 225-262.

Caldwell, John C., I. O. Orubuloye, and Pat Caldwell. 1992. "Fertility decline in Africa: A new type of transition?" Population and Development Review 18(2): 211-242.

Central Statistical Service. 1997. "Census '96: Preliminary estimates of the size of the population of South Africa." Pretoria: Central Statistics.

Cohen, Barney. 1998. "The emerging fertility transition in sub-Saharan Africa," World Development 26(8): 1431-1461.

Frank, Odile and Geoffrey McNicoll. 1987. "An interpretation of fertility and population policy in Kenya," Population and Development Review 13(2): 209-243. 
Garenne, Michel, Stephen Tollman, and Kathleen Kahn. 1999. "Age pattern of adolescent and marital fertility in a rural area of South Africa (Agincourt)," unpublished manuscript, CEPED (Centre Français sur la Population et le Développement), Paris, France.

Kaufman, Carol E. 1996. "The politics and practice of reproductive control in South Africa: A multilevel analysis of fertility and contraceptive use," unpublished doctoral dissertation, Department of Sociology, University of Michigan, Ann Arbor. . 1998. "Changing fertility patterns in South Africa: What is the historical record?" paper presented at the International Union for the Scientific Study of Population seminar on Reproductive Change in sub-Saharan Africa, Nairobi, 2-4 November.

Kaufman, Carol E., Pranitha Maharaj, and Linda Richter. 1998. "Children's schooling in South Africa: Transitions and tensions in households and communities," paper presented at the Annual Meeting of the Population Association of America, Chicago, 2-4 April.

Kaufman, Carol E. and Heston Phillips. 1995. "Methodology, data and history: Research and creativity in South Africa," paper presented at the Conference on Population and Politics in South Africa, University of Michigan, Ann Arbor, 2-4 February.

Kirk, Dudley and Bernard Pillet. 1998. "Fertility levels, trends, and differentials in subSaharan Africa in the 1980s and 1990s," Studies in Family Planning 29(1): 1-22.

Klugman, Barbara. 1988. "Decision-making on contraception amongst a sample of urban African working women," unpublished Master's thesis, Department of Sociology, University of the Witwatersrand, Johannesburg, South Africa.

Lloyd, Cynthia B., Carol E. Kaufman, and Paul Hewett. 1999. "The spread of primary schooling in sub-Saharan Africa: Implications for fertility change," Policy Research Division Working Paper no. 127. New York: Population Council.

McDevitt, Thomas A. 1996. World Population Profile: 1996, with a Special Chapter Focusing on Adolescent Fertility in the Developing World. U.S. Census Bureau, Report WP/96. Washington, DC: US Government Printing Office.

McNeil, Pamela, Freya Olafson, Dorian Powell, and Jean Jackson. 1980. "The adolescent mothers project in Jamaica," Pathpapers no. 7. Chestnut Hill, MA: The Pathfinder Fund. 
Mensch, Barbara S., Judith Bruce, and Margaret E. Greene. 1998. The Uncharted Passage: Girls'Adolescence in the Developing World. New York: Population Council.

Mfono, Zanele. 1998. "Teenage contraceptive needs in urban South Africa: A case study," International Family Planning Perspectives 24(4): 180-183.

Preston-Whyte, Eleanor. 1990. "Qualitative perspectives on fertility trends among African teenagers," in W. P. Mostert and J. M. Lötter (eds.), South Africa's Demographic Future. Pretoria: Human Sciences Research Council.

Preston-Whyte, Eleanor, M. Zondi, G. Mavudla, and H. Gumede. 1991. "Teenage pregnancy, whose problem? Realities and prospects for action in KwaZulu/Natal," Southern African Journal of Demography. Vol. 3.

Preston-Whyte, E. and M. Zondi. 1992. "African teenage pregnancy: Whose problem?" in S. Burman and E. Preston-Whyte (eds.), Questionable Issue: Illegitimacy in South Africa. Cape Town: Oxford University Press.

Richter, Linda. 1996. "A survey of reproductive health issues among urban black youth in South Africa (Final Report)." Pretoria: Centre for Epidemiological Research in South Africa.

Schalekamp, Cecilia. 1998. Personal communication.

Singh, Susheela and Renee Samara. 1996. "Early marriage among women in developing countries," International Family Planning Perspectives 22(4): 148-157, 175.

South African Demographic and Health Survey. 1987-89. Pretoria: Human Sciences Research Council.

South African Demographic and Health Survey, 1998: Preliminary Report. 1999. South African Medical Research Council, South African Department of Health, and Macro International.

Stadler, Jonathan. 1994. "Generational relationship in a lowveld village: Questions of age, household and tradition," Master's thesis, Department of Anthropology, University of the Witwatersrand, Johannesburg, South Africa.

Varga, Christine A. 1997. "Sexual decision-making and negotiation in the midst of AIDS: 
Youth in KwaZulu/Natal, South Africa." Health Transition Review 7(Supplement 3): 45-67.

Varga, C. A. and E. L. Makubalo. 1996. "Sexual (non) negotiation,” Agenda 28: 31-38.

Wood, Katharine and Rachel Jewkes. 1997. "Violence, rape, and sexual coercion: Everyday love in a South African township," Gender and Development 5(2): 41-46.

World Bank. 1986. Population Growth and Policies in Sub-Saharan Africa. Washington, DC: The World Bank.

1993. Effective Family Planning Programs. Washington, DC: The World Bank. 


\section{POLICY RESEARCH DIVISION WORKING PAPERS}

Recent Back Issues

1998

*106 Sajeda Amin and Gilda Sedgh, "Incentive schemes for school attendance in rural Bangladesh."

107 Martin Brockerhoff and Paul Hewett, "Ethnicity and child mortality in sub-Saharan Africa."

108 Ann E. Biddlecom and Bolaji M. Fapohunda, "Covert contraceptive use: Prevalence, motivations, and consequences."

109 John Bongaarts and Griffith Feeney, "On the quantum and tempo of fertility."

110 Barbara S. Mensch, Daniel Bagah, Wesley H. Clark, and Fred Binka, "The changing social environment for adolescents in the Kassena-Nankana District of northern Ghana: Implications for reproductive behavior."

111 Martin Brockerhoff and Ann Biddlecom, "Migration, sexual behavior, and HIV diffusion in Kenya."

112 Zeba A. Sathar and John B. Casterline, "The onset of fertility transition in Pakistan."

113 Geoffrey McNicoll, "Government and fertility in transitional and posttransitional societies."
114 John Bongaarts, "Fertility and reproductive preferences in post-transitional societies."

115 Fiona Steele, Sajeda Amin, and Ruchira T. Naved, "The impact of an integrated micro-credit program on women's empowerment and fertility behavior in rural Bangladesh."

*116 Cynthia B. Lloyd, Barbara S. Mensch, and Wesley H. Clark, "The effects of primary-school quality on the educational participation and attainment of Kenyan girls and boys."

117 Sajeda Amin and Cynthia B. Lloyd, "Women's lives and rapid fertility decline: Some lessons from Bangladesh and Egypt."

118 James F. Phillips and Mian Bazle Hossain, "The impact of family planning household service delivery on women's status in Bangladesh."

119 Mark R. Montgomery and John B. Casterline, "Social networks and the diffusion of fertility control."

* No longer available 
*120 John Bongaarts, "The fertility impact of changes in the timing of childbearing in the developing world."

*121 James F. Phillips, Wendy L. Greene, and Elizabeth F. Jackson, "Lessons from community-based distribution of family planning in Africa."

122 Mark R. Montgomery, "Mortality decline and the demographic response: Toward a new agenda."

123 Mark R. Montgomery, Mary ArendsKuenning, and Cem Mete, "The quantity-quality transition in Asia."

124 Barbara S. Mensch, Wesley H. Clark, Cynthia B. Lloyd, and Annabel S. Erulkar, "Premarital sex and school dropout in Kenya: Can schools make a difference?"

125 John Bongaarts and Rodolfo A. Bulatao, "Completing the demographic transition."

126 Geoffrey McNicoll, "Population weights in the international order."
127 Cynthia B. Lloyd, Carol E. Kaufman, and Paul Hewett, "The spread of primary schooling in sub-Saharan Africa: Implications for fertility change."

128 John B. Casterline, "The onset and pace of fertility transition: National patterns in the second half of the twentieth century."

129 Mark R. Montgomery, Michele Gragnolati, Kathleen Burke, and Edmundo Paredes, "Measuring living standards with proxy variables."

130 Bamikale Feyisetan and John B. Casterline, "Fertility preferences and contraceptive change in developing countries."

131 Martin Brockerhoff, "Urban growth in developing countries: A review of projections and predictions."

132 Omaima El-Gibaly, Barbara Ibrahim, Barbara S. Mensch, and Wesley H. Clark, "The decline of female circumcision in Egypt: Evidence and interpretation."

* No longer available 
133 Mary Arends-Kuenning and Sajeda Amin, "The effects of schooling incentive programs on household resource allocation in Bangladesh."

134 John Bongaarts and Charles F. Westoff, "The potential role of contraception in reducing abortion."
135 John B. Casterline and Steven W. Sinding, "Unmet need for family planning in developing countries and implications for population policy."

136 Carol E. Kaufman, Thea de Wet, and Jonathan Stadler, "Adolescent pregnancy and parenthood in South Africa." 